\title{
A grid-independent EMMS/bubbling drag model for bubbling and turbulent fluidization
}

\author{
Luo, Hao; Lu, Bona; Zhang, Jingyuan; Wu, Hao; Wang, Wei
}

Published in:

Chemical Engineering Journal

Link to article, DOI:

10.1016/j.cej.2017.04.145

Publication date:

2017

Document Version

Peer reviewed version

Link back to DTU Orbit

Citation (APA):

Luo, H., Lu, B., Zhang, J., Wu, H., \& Wang, W. (2017). A grid-independent EMMS/bubbling drag model for bubbling and turbulent fluidization. Chemical Engineering Journal, 326, 47-57.

https://doi.org/10.1016/j.cej.2017.04.145

\section{General rights}

Copyright and moral rights for the publications made accessible in the public portal are retained by the authors and/or other copyright owners and it is a condition of accessing publications that users recognise and abide by the legal requirements associated with these rights.

- Users may download and print one copy of any publication from the public portal for the purpose of private study or research.

- You may not further distribute the material or use it for any profit-making activity or commercial gain

- You may freely distribute the URL identifying the publication in the public portal

If you believe that this document breaches copyright please contact us providing details, and we will remove access to the work immediately and investigate your claim. 
Abstract modeling of drag coefficient and thus improves coarse-grid simulation of bubbling and turbulent fluidized beds. However, its dependence on grid size has not been fully investigated. In this article, we adopt a two-step scheme to extend the EMMS/bubbling model to the sub-grid level. Thus the heterogeneity index, $H_{\mathrm{D}}$, which accounts for the hydrodynamic disparity between homogeneous and heterogeneous fluidization, can be correlated as a function of both local voidage and slip velocity. Simulations over a periodic domain show the new drag model is less sensitive to grid size because of the additional dependence on local slip velocity. When applying the new drag model to simulations of realistic bubbling and turbulent fluidized beds, we find grid-independent results are easier to obtain for high-velocity turbulent fluidized bed cases. The simulation results indicate that 
scale fluidized beds.

Keywords: fluidized bed; EMMS; simulation; grid dependence; drag coefficient; CFD

\section{Introduction}

Gas-solid fluidization has wide applications in various industries, such as fluid catalytic cracking (FCC), methanol to olefins (MTO), coal gasification and combustion, owing to its advantages in gas-particle contact, heat and mass transfer, and operating flexibility. With the increase of gas velocity, fluidization regime may experience a series of transitions covering homogenous expansion, bubbling fluidization, turbulent fluidization, fast fluidization and pneumatic conveying [1-3]. Different flow regimes are characterized by different meso-scale structures, such as bubbles or voids in bubbling and turbulent fluidization $[4,5]$, and particle clusters in the so-called fast fluidization $[1,6,7]$. These meso-scale structures are recognized to have big impact on the momentum, heat and mass transfer as well as reactions, thus should be taken into account in modeling.

Of various computational fluid dynamic (CFD) approaches, the Eulerian-Eulerian two-fluid model (TFM) requires the least computational resources, and thus, is widely used for simulating large-scale fluidized bed reactors. However, there are still controversial opinions on the applicability of the local equilibrium assumption underlying the TFM [8-10]. In addition, when the TFM is used with coarse-grid resolution in industrial applications, the grid size could be over one hundred times the particle diameter, as in the cases of Lu et al. [11], Schneiderbauer et al. [12] and Shah et al. [13]. Such coarse-grid resolution, if without sub-grid modeling, may greatly reduce the accuracy of simulation $[7,11,13,14]$. 
In recent years, the effect of sub-grid meso-scale structures on the drag has received much attention $[1,15-20]$. Among these researches, the energy-minimization multi-scale (EMMS) approach has been found successful in correcting the drag and predicting the flow distribution in circulating fluidized bed (CFB) of fine particles [11, 21-23]. In the EMMS model, the heterogeneous gas-particle flow was characterized by the meso-scale structure consisting of a particle-rich dense phase in form of clusters and a gas-rich dilute phase in form of dispersed particles. Eight parameters $\left(\varepsilon_{\mathrm{gc}}, U_{\mathrm{gc}}, U_{\mathrm{sc}}, \varepsilon_{\mathrm{gf}}, U_{\mathrm{gf}}, U_{\mathrm{sf}}, f, d_{\mathrm{cl}}\right)$ were assigned to quantify such meso-scale structure and were closed by six equations including mass and momentum conservations and a stability condition $N_{\mathrm{st}} \rightarrow \min$ [15]. To couple the EMMS model with CFD, Yang et al. [24, 25] introduced an acceleration term for both dense and dilute phases and then obtained a structuredependent EMMS drag. Wang and Li [1] further proposed a two-step scheme called EMMS/matrix, in which the meso-scale parameters $\left(\varepsilon_{\mathrm{gc}}, d_{\mathrm{cl}}\right)$ were determined at the global reactor scale through solving a set of conservation equations and the stability condition, while the remaining variables were determined in the second step by satisfying local conservation equations within computational cells, thereby the drag correction in term of the heterogeneity index, $H_{\mathrm{D}}=\beta / \beta_{0}$, was found to be a function of local slip velocity $u_{\mathrm{r}}$ and local voidage $\varepsilon_{\mathrm{g}}$. In contrast, pervious meso-scale models [24, 25] were found to result in heterogeneity index as only a function of voidage. This additional dependence of drag correction on the slip velocity was considered to be critical to reduce the sensitivity of CFD simulation on grid resolution $[16,26]$. Indeed some other researches also confirmed that the drag correction should not only depend on voidage but also on slip velocity [19, 26], and such additional dependency on slip velocity was helpful to obtain grid-independent results and improve accuracy [27]. 
To extend the application of the EMMS model to the realm of bubbling fluidization, Shi et al.

3 [4] and Hong et al. [5] introduced bubbles in place of the particle clusters to characterize the meso-

4 scale structure. This drag model called EMMS/bubbling model improved CFD performance for

5 both bubbling and turbulent fluidized beds $[5,28]$.However, its dependence on the grid size has not

6 been fully investigated. In particular, whether this grid dependence can be reduced by introducing

7 the factor of local slip velocity $\left(U_{\mathrm{r}}\right)$, as in the case of EMMS/matrix drag model, remains to be

8 explored.

following the two-step scheme of the EMMS/matrix drag model. Then, a series of simulations are carried out in the 2D periodic domain to test the grid dependence of the new EMMS/bubbling drag model. Finally, this two-step EMMS/bubbling drag model is tested through simulations of a bubbling fluidized bed and two turbulent fluidized beds.

\section{Extension of EMMS/bubbling model to sub-grid level}

\subsection{Model derivation}

In this work, we try to develop a new drag model based on the work of Hong et al. [5]. In the EMMS/bubbling model [5], monodisperse gas-solid flow is resolved into a dense phase (emulsion, denoted by subscript c) and a dilute phase (bubble, denoted by subscript f). There are seven equations and a stability condition to close ten variables, i.e., $U_{\mathrm{gc}}, U_{\mathrm{sc}}, a_{\mathrm{sc}}$ and $\varepsilon_{\mathrm{gc}}$ for the dense phase, $U_{\mathrm{gf}}, U_{\mathrm{sf}}, a_{\mathrm{sf}}$ and $\varepsilon_{\mathrm{gf}}$ for the dilute phase and $f$ and $d_{\mathrm{b}}$ for the interphase. 
1 follows

$2 f F_{\mathrm{dc}}+F_{\mathrm{di}}=\frac{3}{4} C_{\mathrm{dc}} \frac{f\left(1-\varepsilon_{\mathrm{gc}}\right)}{d_{\mathrm{p}}} \rho_{g} U_{\mathrm{rc}}^{2}+\frac{3}{4} C_{\mathrm{db}} \frac{1-f}{d_{b}} \rho_{\mathrm{c}} U_{\mathrm{ri}}^{2}=f\left(1-\varepsilon_{\mathrm{gc}}\right)\left(\rho_{\mathrm{s}}-\rho_{\mathrm{g}}\right)\left(g+a_{\mathrm{sc}}\right)$,

$3 \quad F_{\mathrm{df}}=\frac{3}{4} C_{\mathrm{df}} \frac{1-\varepsilon_{\mathrm{gf}}}{d_{\mathrm{p}}} \rho_{\mathrm{g}} U_{\mathrm{rf}}^{2}=\left(1-\varepsilon_{\mathrm{gf}}\right)\left(\rho_{\mathrm{s}}-\rho_{\mathrm{g}}\right)\left(g+a_{\mathrm{sf}}\right)$.

4 Pressure balance of different phases [5],

$5 \quad F_{\mathrm{df}}+\frac{F_{\mathrm{di}}}{1-f}=F_{\mathrm{dc}}$.

6 The mass balances for the gas and solid phases require that

$7 \quad U_{\mathrm{g}}=f U_{\mathrm{gc}}+(1-f) U_{\mathrm{gf}}$,

$8 \quad U_{\mathrm{s}}=f U_{\mathrm{sc}}+(1-f) U_{\mathrm{sf}}$,

9 The mean voidage is related to the dense-phase and dilute-phase voidages by

10

$\varepsilon_{\mathrm{g}}=f \varepsilon_{\mathrm{gc}}+(1-f) \varepsilon_{\mathrm{gf}}$.

11 The bubble diameter, as in our previous work, follows the correlation of Horio and Nonaka [29],

12 which was reported applicable to a variety of powders [29-32].

13 $d_{\mathrm{b}}=\left[-\gamma_{\mathrm{m}}+\left(\gamma_{\mathrm{m}}^{2}+4 d_{\mathrm{bm}} / D_{\mathrm{t}}\right)^{0.5}\right]^{2} D_{\mathrm{t}} / 4$

where

15

$\gamma_{\mathrm{m}}=0.0256 \sqrt{\left(D_{\mathrm{t}} / g\right)} / U_{\mathrm{mf}}, \quad d_{\mathrm{bm}}=2.59 g^{-0.2}\left[\left(U_{\mathrm{g}}-U_{\mathrm{gc}}\right) \pi D_{\mathrm{t}}^{2} / 4\right]^{0.4}$.

The above equations are assumed to satisfy the stability condition in term of the minimization

of normalized $N_{\text {st }}$, the mass-specific energy consumption rate for suspending particles, as follows:

$18 \quad \frac{N_{\mathrm{st}}}{N_{\mathrm{T}}}=\left(\frac{f F_{\mathrm{dc}} U_{\mathrm{gc}}+(1-f) F_{\mathrm{df}} U_{\mathrm{gf}}}{\left(1-\varepsilon_{\mathrm{g}}\right) \rho_{\mathrm{s}}}+(1-f) \varepsilon_{\mathrm{gf}} U_{\mathrm{g}} g / \varepsilon_{\mathrm{g}}\right) /\left(\frac{\left(\rho_{\mathrm{s}}-\rho_{\mathrm{g}}\right)}{\rho_{\mathrm{s}}} g U_{\mathrm{g}}\right) \rightarrow \min$.

Table 1 Summary of parameters and definitions in EMMS/bubbling model (adapted from Hong et 


Dilute phase Dense phase Inter-phase

Characteristic

$d_{\mathrm{p}} \quad d_{\mathrm{p}} \quad d_{\mathrm{b}}$

diameter

Voidage

$\varepsilon_{\mathrm{gf}} \quad \varepsilon_{\mathrm{gc}}$

$1-f$

Superficial relative

$$
U_{\mathrm{rf}}=U_{\mathrm{gf}}-\frac{U_{\mathrm{sf}} \varepsilon_{\mathrm{gf}}}{\varepsilon_{\mathrm{sf}}} \quad U_{\mathrm{rc}}=U_{\mathrm{gc}}-\frac{U_{\mathrm{sc}} \varepsilon_{\mathrm{gc}}}{\varepsilon_{\mathrm{sc}}} \quad U_{\mathrm{ri}}=f\left(U_{\mathrm{f}}-U_{\mathrm{c}}\right)
$$

velocity

Reynolds number

$$
R e_{\mathrm{f}}=\frac{\rho_{\mathrm{g}} d_{\mathrm{p}} U_{\mathrm{rf}}}{\mu_{\mathrm{g}}}
$$

$R e_{\mathrm{c}}=\frac{\rho_{\mathrm{g}} d_{\mathrm{p}} U_{\mathrm{rc}}}{\mu_{\mathrm{g}}}$

$R e_{\mathrm{i}}=\frac{\rho_{\mathrm{c}} d_{\mathrm{b}} U_{\mathrm{ri}}}{\mu_{\mathrm{c}}}$

Standard drag

coefficient

$$
C_{\mathrm{df} 0}=\frac{24}{R e_{\mathrm{f}}}+\frac{3.6}{R e_{\mathrm{f}}^{0.313}} \quad C_{\mathrm{dc} 0}=\frac{24}{R e_{\mathrm{c}}}+\frac{3.6}{R e_{\mathrm{c}}^{0.313}} \quad \begin{cases}C_{\mathrm{db} 0}=38 R e_{\mathrm{i}}^{-1.5} & \left(0<R e_{\mathrm{i}} \leq 1.8\right) \\ C_{\mathrm{db} 0}=2.7+\frac{24}{R e_{\mathrm{i}}} & \left(R e_{\mathrm{i}}>1.8\right)\end{cases}
$$

Effective drag

$$
C_{\mathrm{df}}=C_{\mathrm{d} 00} \varepsilon_{\mathrm{gf}}^{-4.65} \quad C_{\mathrm{dc}}=C_{\mathrm{dc} 0} \varepsilon_{\mathrm{gc}}^{-4.65} \quad C_{\mathrm{db}}=C_{\mathrm{db} 0} f^{-0.5}
$$

coefficient
Number density
$m_{\mathrm{f}}=\frac{1-\varepsilon_{\mathrm{gf}}}{\pi d_{\mathrm{p}}^{3} / 6}$
$m_{\mathrm{c}}=\frac{1-\varepsilon_{\mathrm{gc}}}{\pi d_{\mathrm{p}}^{3} / 6}$
$m_{\mathrm{i}}=\frac{1-f}{\pi d_{\mathrm{b}}^{3} / 6}$

Drag force on each

particle or bubble

$$
F_{\mathrm{f}}=C_{\mathrm{df}} \frac{\pi d_{\mathrm{p}}^{2}}{4} \frac{\rho_{\mathrm{g}}}{2} U_{\mathrm{rf}}^{2} \quad F_{\mathrm{f}}=C_{\mathrm{dc}} \frac{\pi d_{\mathrm{p}}^{2}}{4} \frac{\rho_{\mathrm{g}}}{2} U_{\mathrm{rc}}^{2} \quad F_{\mathrm{i}}=C_{\mathrm{db}} \frac{\pi d_{\mathrm{b}}^{2}}{4} \frac{\rho_{\mathrm{c}}}{2} U_{\mathrm{ri}}^{2}
$$

Drag force in unit

$$
F_{\mathrm{df}}=m_{\mathrm{f}} F_{\mathrm{f}} \quad F_{\mathrm{dc}}=m_{\mathrm{c}} F_{\mathrm{c}} \quad F_{\mathrm{di}}=m_{\mathrm{i}} F_{\mathrm{i}}
$$

volume two-step scheme of the EMMS/matrix drag model, in the first step, we calculate the meso-scale

* The mean velocities of the dilute and dense phases are defined as $U_{\mathrm{f}}=\left(\rho_{\mathrm{g}} U_{\mathrm{gf}}+\rho_{\mathrm{s}} U_{\mathrm{sf}}\right) / \rho_{\mathrm{b}}$ and $U_{\mathrm{c}}=\left(\rho_{\mathrm{g}} U_{\mathrm{gc}}+\rho_{\mathrm{s}} U_{\mathrm{sc}}\right) / \rho_{\mathrm{c}}$, respectively, where $\rho_{b}, \rho_{\mathrm{c}}$ and $\mu_{\mathrm{c}}$ are expressed as $\rho_{b}=\varepsilon_{\mathrm{g}} \rho_{\mathrm{g}}+\varepsilon_{\mathrm{f}} \rho_{\mathrm{s}}, \rho_{\mathrm{c}}=\varepsilon_{\mathrm{gc}} \rho_{\mathrm{g}}+\varepsilon_{\mathrm{sc}} \rho_{\mathrm{s}}$, and $\mu_{\mathrm{c}}=\mu_{\mathrm{g}}\left[1+2.5 \varepsilon_{\mathrm{sc}}+10.05 \varepsilon_{\mathrm{sc}}{ }^{2}+0.00273 \exp \left(16.6 \varepsilon_{\mathrm{sc}}\right)\right]$, respectively.

The related definitions and model parameters are summarized in Table 1. Similar to the structure parameters ( $\left.\varepsilon_{\mathrm{gc}}, d_{\mathrm{b}}\right)$ by solving the set of conservation equations and the stability condition, 
1 Eqs.(1) to (8) at the reactor level under the given superficial gas velocity. The scheme for this first

2 step is referred to Hong et al [5]. $\varepsilon_{\mathrm{gc}}$ and $d_{\mathrm{b}}$ can thus be expressed as a function of voidage. As

3 indicated in the EMMS/matrix model, the voidage in bubbles tends to $\varepsilon_{\max }\left(\varepsilon_{\max }=0.9997\right)$ and $a_{\text {sf }}$

4 tends to $-g$. Then, the remaining variables, i.e. $\left(U_{\mathrm{gc}}, U_{\mathrm{sc}}, a_{\mathrm{sc}}, f\right)$ for the dense phase and $\left(U_{\mathrm{gf}}, U_{\mathrm{sf}}\right)$ for

5 the dilute phase, can be determined in the second step by solving the conservation equations (Eqs.

6 (1) (6)) locally within each grid. As indicated in Lu et al. [16], the velocities $U_{\mathrm{gc}}, U_{\mathrm{sc}}, U_{\mathrm{gf}}, U_{\mathrm{sf}}$ can

7 be further reduced to two slip velocities $\left(U_{\text {ri }}, U_{\text {rc }}\right)$ by combining the definitions of superficial

8 velocities as shown in Table 1 and the equations (Eqs.(4) (6)). The relationship between two slip

9 velocities $\left(U_{\text {ri }}, U_{\text {rc }}\right)$ can be expressed as Eq. (9),

$U_{\mathrm{ri}}=\frac{f\left(1-\varepsilon_{\mathrm{g}}\right)}{(1-f)\left(\varepsilon_{\mathrm{gf}}-\varepsilon_{\mathrm{g}}\right)}\left(U_{\mathrm{r}}-f U_{\mathrm{rc}}-\frac{\rho_{\mathrm{g}}(1-f)\left(\varepsilon_{\mathrm{gf}}-\varepsilon_{\mathrm{g}}\right)}{\rho_{\mathrm{c}}\left(1-\varepsilon_{\mathrm{g}}\right)} U_{\mathrm{rc}}\right)$.

11 The detailed derivation of Eq.(9) is provided in Supplementary material. Finally, four

12 unknown parameters $\left(f, U_{\mathrm{rc}}, U_{\mathrm{ri}}, a_{\mathrm{sc}}\right)$ in the second step are closed by four equations, Eqs. (1), (3),

13 (6) and (9).

With the meso-scale parameters $\left(\varepsilon_{\mathrm{gc}}, d_{\mathrm{b}}\right)$ resolved in the first step, the scheme of the second step is described as follows:

(1) traverse over trial values of local parameters, $U_{\mathrm{r}}$ and $\varepsilon_{\mathrm{g}}$,

(2) calculate the volume fraction of dense phase $f$ from Eq. (6),

(3) calculate $U_{\text {rc }}$ and $U_{\text {ri }}$ from Eq. (3) and Eq. (9),

(4) calculate $a_{\mathrm{sc}}$ from Eq. (1).

Through above four steps, all parameters are solved and the structure-dependent drag coefficient are obtained as follows. 


$$
\begin{aligned}
\beta & =\frac{\varepsilon_{\mathrm{g}}^{2}}{U_{\mathrm{r}}}\left[f F_{\mathrm{dc}}+(1-f) F_{\mathrm{df}}+F_{\mathrm{di}}\right] \\
& =\frac{\varepsilon_{\mathrm{g}}^{2}}{U_{\mathrm{r}}}\left(\rho_{\mathrm{s}}-\rho_{\mathrm{g}}\right)\left[f\left(1-\varepsilon_{\mathrm{gc}}\right)\left(g+a_{\mathrm{sc}}\right)+(1-f)\left(1-\varepsilon_{\mathrm{gf}}\right)\left(g+a_{\mathrm{sf}}\right)\right]
\end{aligned}
$$

3 And the heterogeneity index, $H_{\mathrm{D}}$, is defined by

$$
4 \quad H_{\mathrm{D}}=\frac{\beta}{\beta_{0}}
$$

5 where

$6 \quad \beta_{0}=\frac{3}{4} C_{\mathrm{d} 0} \frac{\varepsilon_{\mathrm{g}}\left(1-\varepsilon_{\mathrm{g}}\right)}{d_{\mathrm{p}}} \rho_{\mathrm{g}}\left|u_{\mathrm{g}}-u_{\mathrm{s}}\right| \varepsilon_{\mathrm{g}}^{-2.65}$. expressed as a function of local slip velocity $\left(\mathrm{Re}=U_{\mathrm{r}} \rho_{\mathrm{g}} d_{\mathrm{p}} / \mu_{\mathrm{g}}\right)$ and voidage. As shown in Fig. 1 , The drag coefficient is much less than the homogenous one within most of the voidage range, except

10 near the two ends corresponding to the packed state and extremely dilute flow, respectively.

11 Higher slip velocity generally results in higher values of $H_{\mathrm{D}}$, and the previous version of EMMS/bubbling drag (Hong et al. [5]) can thus be viewed as a particular case of this work when the local superficial slip velocity $U_{\mathrm{r}}$ is equal to the global superficial slip velocity $14\left(U_{\mathrm{g}}-G_{\mathrm{s}} \varepsilon_{\mathrm{g}} /\left(1-\varepsilon_{\mathrm{g}}\right) / \rho_{\mathrm{s}}\right)$. To facilitate its coupling with CFD code, $H_{\mathrm{D}}$ is fitted in the form of $H_{\mathrm{D}}=a \operatorname{Re}^{(b \operatorname{Re}+c)}$, where $a, b$, and $c$ are all functions of voidage. 

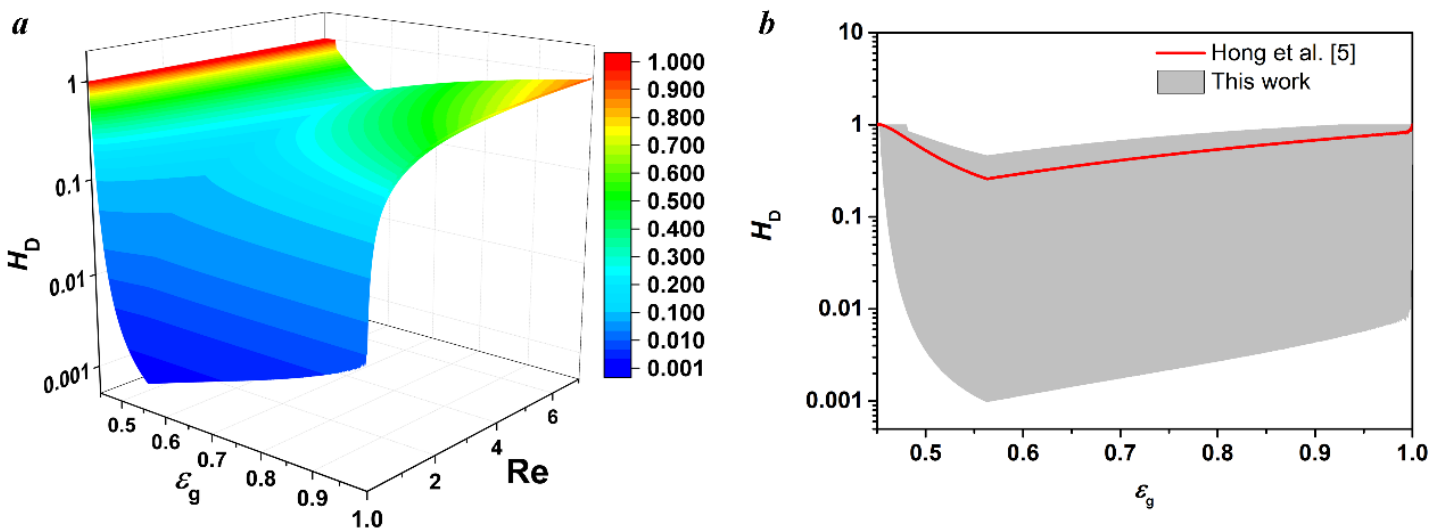

Fig. 1 The heterogeneity index $\left(H_{\mathrm{D}}\right)$ of $(a)$ new EMMS/bubbling model for a bubbling fluidized bed and its comparison with that of (b) Hong et al. [5] (Dubrawski et al. [33]: $\rho_{\mathrm{g}}=1.225 \mathrm{~kg} / \mathrm{m}^{3}$, $\left.\rho_{\mathrm{p}}=1560 \mathrm{~kg} / \mathrm{m}^{3}, d_{\mathrm{p}}=103 \mu \mathrm{m}, \mu_{\mathrm{g}}=1.8 \times 10^{-5} \mathrm{~Pa} \cdot \mathrm{s}, U_{\mathrm{g}}=0.5 \mathrm{~m} / \mathrm{s}, \varepsilon_{\mathrm{mf}}=0.45, G_{\mathrm{s}}=0, D_{\mathrm{t}}=0.133\right)$

\section{Sensitivity to grid size}

\subsection{Simulation settings}

The grid size has significant effects on the simulation results [7, 19, 34]. To test the grid dependence when applying the new drag model, we chose a 2D doubly periodic domain with dimension comparable to a typical coarse grid in TFM simulations, as in the work of Lu et al. [16] and Agrawal et al. [7].

Square grids were generated uniformly by using Gambit ${ }^{\circledR} 2.4$, and ANSYS Fluent ${ }^{\circledR} 15$ was used as the CFD solver. Two different solid concentrations, i.e., $\varepsilon_{\mathrm{s}}=0.05$ and $\varepsilon_{\mathrm{s}}=0.2$, were adopted to represent the dilute and dense flow. Fine particles were distributed uniformly in the domain at the beginning. The pressure drop in the vertical direction was specified to be equal to the gravity of solid particles. Both gas and solid phases were initialized with zero velocity and then a perturbation was introduced. Following many previous researches, to mention but a few, Agrawal et al. [7], Igci et al. [34], and Lu et al. [16], the time series of slip velocity of y-direction were monitored to 
1 observe its fluctuation. After a period of time, the quasi-steady state was reached where the

2 time-averaged slip velocity kept almost unchanged, then statistical analysis could be started to

3 determine the time-averaged quantities. In this study, all simulations over the periodic domain ran

4 for 8 seconds and the last 4 seconds were collected for time-averaged statistics. Implicit formulation

5 was adopted to solve the volume fraction equation, since it reached pseudo-steady state faster than

6 explicit formulations [35]. The physical time step $2 \times 10^{-4} \mathrm{~s}$ chosen in present work was based on the

7 work of Lu et al [16]. However, for the case of the finest grid (128×512), using such a time step

8 causes convergence difficulty, thus, a smaller physical time step $5 \times 10^{-5} \mathrm{~s}$ was chosen. The

9 Favre-averaged slip velocity over the domain, as applied in Agrawal et al. [7], was used to quantify

10 the effects of meso-scale structure on the drag, and defined by

$11 \quad \bar{u}_{\mathrm{r}}=\frac{1}{N} \sum_{1}^{N}\left(\frac{\varepsilon_{\mathrm{g}(\mathrm{i})} u_{\mathrm{g}(\mathrm{i})}}{\bar{\varepsilon}_{\mathrm{g}}}-\frac{\varepsilon_{\mathrm{s}(\mathrm{i})} u_{\mathrm{s}(\mathrm{i})}}{\bar{\varepsilon}_{\mathrm{s}}}\right)$,

12 Where $N$ is the number of cells. More simulations settings are shown in Table 2 and the drag

13 formulations are provided in Table B.2 of Supplementary material. Although the correction of this

14 work is complicated, the computational time does not increase too much as they only involve

15 algebraic calculation. According to our experience, the simulation time of using the model of

16 Hong et al. [5] and this work are almost the same.

17 Table 2 Parameters settings for simulations in a periodic domain.
Particle diameter, $\mu \mathrm{m}$
97
Particle density, $\mathrm{kg} / \mathrm{m}^{3}$
1500
Gas density, $\mathrm{kg} / \mathrm{m}^{3}$
0.6747
Gas viscosity, $\mathrm{Pa} \cdot \mathrm{s}$
$2.7782 \times 10^{-5}$
Domain size, $\mathrm{mm}^{2}$
$25 \times 100$
Number of grids
$4 \times 16,8 \times 32,16 \times 64,32 \times 128,64 \times 256,128 \times 512$ 
Restitution coefficient

Drag coefficients

Physical time-step
0.9

Hong et al. [5]/This work.

$2 \times 10^{-4} \mathrm{~s}, 5 \times 10^{-5} \mathrm{~s}$
1

\subsection{Results and discussions}

Fig.2 shows the variation of time-averaged axial slip velocity against grid size for two solid concentrations. To the left of the figure, the y-coordinates are scaled with the terminal velocity of a single particle $\left(u_{\mathrm{t}}=0.255 \mathrm{~m} / \mathrm{s}\right)$, and to the right, $\mathrm{y}$-coordinates are scaled with the time-averaged slip velocity of the coarsest-grid case $\left(6.25 \times 6.25 \mathrm{~mm}^{2}\right)$. X-abscissas are scaled with the particle diameter, $d_{\mathrm{p}}$.

For the case of $\varepsilon_{\mathrm{s}}=0.05$, the slip velocities keep changing until the grid size decreases to $4 d_{\mathrm{p}}$. During grid refinement, the dimensionless slip velocity $\left(u_{\mathrm{r}} / u_{\mathrm{t}}\right)$ predicted by using the drag of Hong et al. [5] changes from three to five. By comparison, the change predicted by using our new drag is much smaller.

For the case of $\varepsilon_{\mathrm{s}}=0.2$, the slip velocity predicted by using the drag of Hong et al. [5] converges to its asymptotic value again at the grid size of about $4 d_{\mathrm{p}}$, whereas the sensitivity to the grid size is weaker compared to the dilute flow case $\left(\varepsilon_{\mathrm{s}}=0.05\right)$. And our new drag model shows even weaker dependence on the grid size. That implies a coarser grid could be applied when using our new drag based on two-step scheme. 

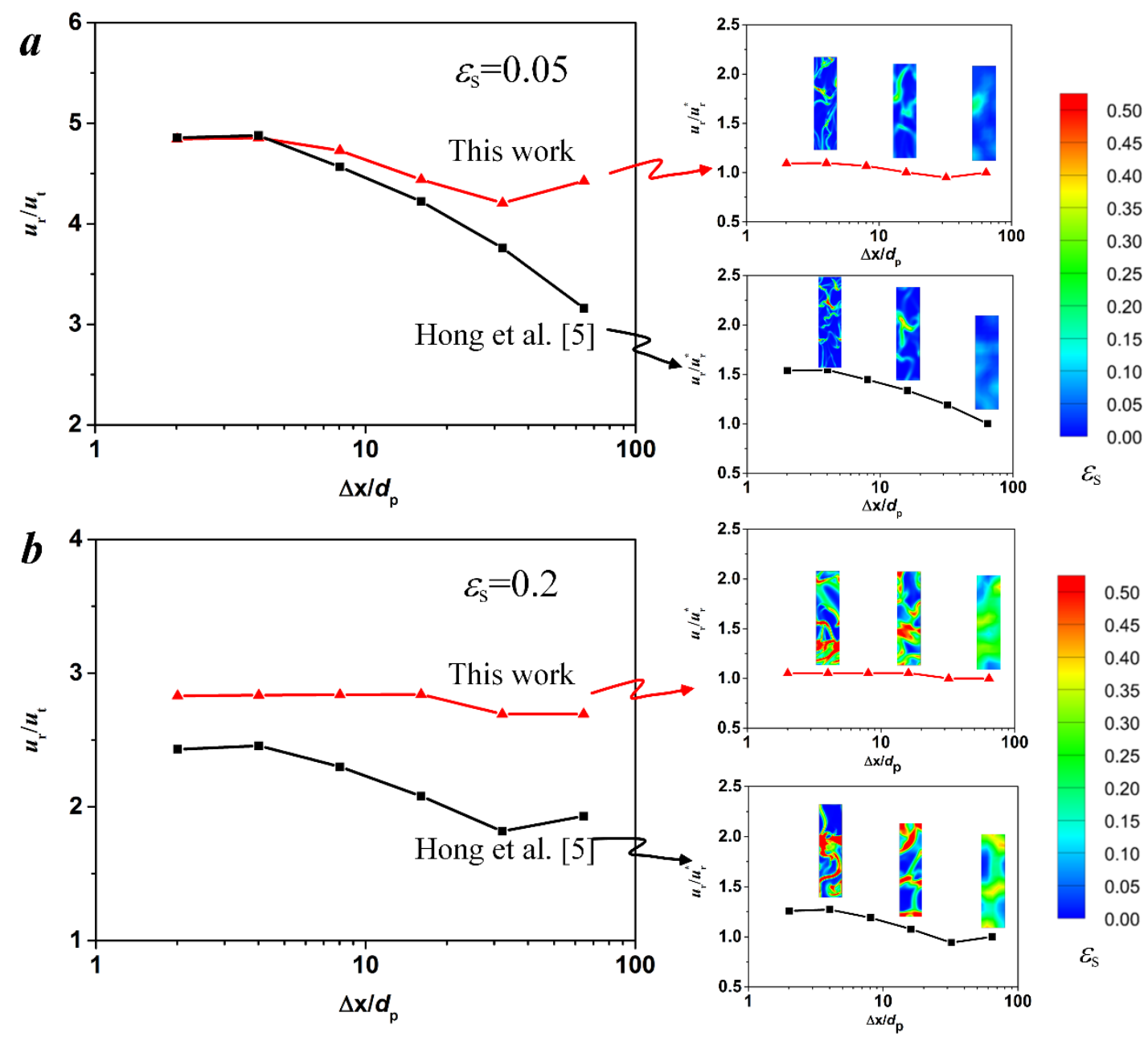

2 Fig. 2 Effect of grid resolution on time-averaged axial slip velocity with snapshots of solids

3 distribution. $u_{\mathrm{r}}{ }^{*}$ is the time-averaged axial slip velocity over the largest grid scheme for each case

4 in simulations. The drag coefficients of EMMS/bubbling model and this work are based on the

5 following operating conditions $\left(\rho_{\mathrm{g}}=0.6747 \mathrm{~kg} / \mathrm{m}^{3}, \rho_{\mathrm{p}}=1500 \mathrm{~kg} / \mathrm{m}^{3}, d_{\mathrm{p}}=97 \mu \mathrm{m}, \mu_{\mathrm{g}}=2.7782 \times 10^{-5} \mathrm{~Pa} \cdot \mathrm{s}\right.$,

$\left.6 \quad \varepsilon_{\mathrm{mf}}=0.4, U_{\mathrm{g}}=0.8864 \mathrm{~m} / \mathrm{s}, G_{\mathrm{s}}=1.5 \mathrm{~kg} /\left(\mathrm{m}^{2} \mathrm{~s}\right), D_{\mathrm{t}}=10.5 \mathrm{~m}\right):(a) \varepsilon_{\mathrm{s}}=0.05 ;(b) \varepsilon_{\mathrm{s}}=0.2$.

To further evaluate the effect of the slip velocity factor in the new drag model, we performed

11 a series of simulations of three fluidized beds by using the EMMS/bubbling drag with and without 
1 slip factor. These three fluidized beds operate over regimes from bubbling fluidized bed

2 (Dubrawski et al. [33]) to turbulent fluidized bed (Venderbosch [6], Gao et al. [36]). Fig. 3 shows

3 their geometries and Table 3 lists the material properties and operating conditions.

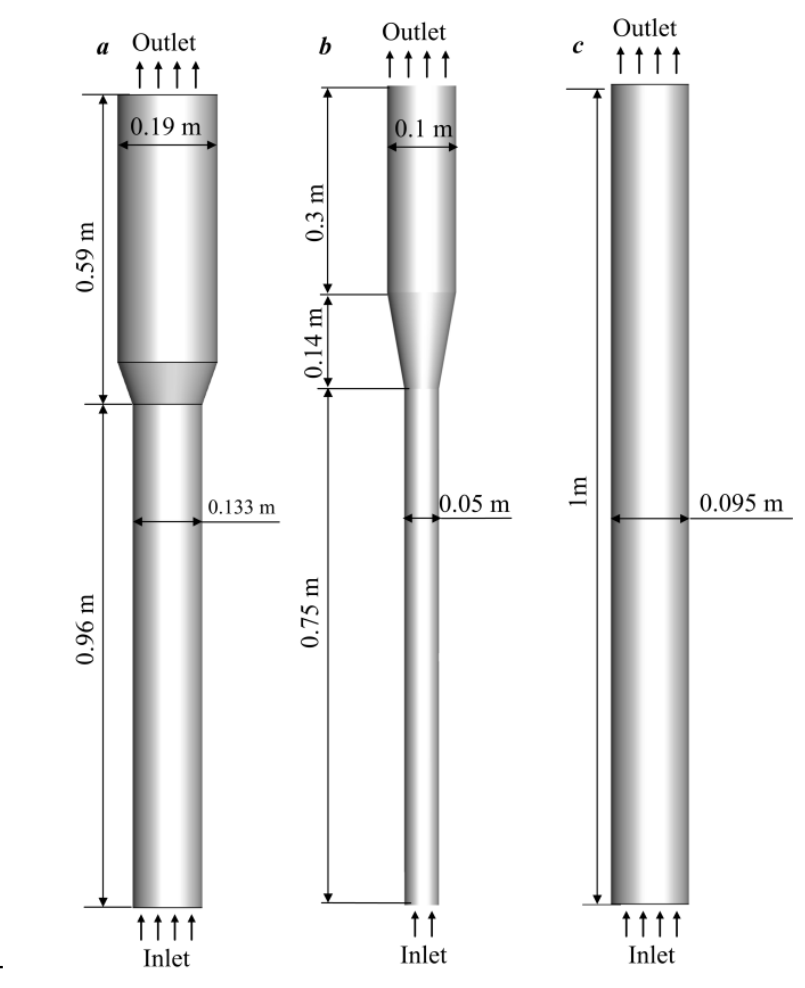

5 Fig. 3 Schematic diagrams of the simulated fluidized beds: $(a)$ bubbling fluidized bed from

6 Dubrawski et al. [33], (b) turbulent fluidized bed from Venderbosch [6], (c) turbulent fluidized bed

7 from Gao et al. [36].

8

9 Table 3 Material properties and operating conditions of the selected fluidized beds

\begin{tabular}{llll}
\hline Parameters & Dubrawski et al. [33] & Venderbosch [6] & Gao et al. [36] \\
\hline$d_{\mathrm{p}}(\mathrm{m})$ & $10.3 \times 10^{-5}$ & $9.0 \times 10^{-5}$ & $13.9 \times 10^{-5}$ \\
$\rho_{\mathrm{s}}\left(\mathrm{kg} / \mathrm{m}^{3}\right)$ & 1560 & 1375 & 2400 \\
$\rho_{\mathrm{g}}\left(\mathrm{kg} / \mathrm{m}^{3}\right)$ & 1.225 & 1.225 & 1.225 \\
$\mu_{\mathrm{g}}(\mathrm{Pa} . \mathrm{s})$ & $1.8 \times 10^{-5}$ & & $1.7894 \times 10^{-5}$ \\
\hline
\end{tabular}




\begin{tabular}{llll}
\hline$\varepsilon_{\mathrm{mf}}$ & 0.45 & 0.4 & 0.4 \\
$U_{\mathrm{g}}(\mathrm{m} / \mathrm{s})$ & 0.4 & 0.6 & 1.25 \\
$u_{\mathrm{t}}(\mathrm{m} / \mathrm{s})$ & 0.381 & 0.277 & 0.843 \\
$U_{\mathrm{g} / u_{\mathrm{t}}}$ & 1.049 & 2.166 & 1.48 \\
\hline
\end{tabular}

1

ANSYS Fluent ${ }^{\circledR} 15$ was used as the CFD solver. For the bubbling fluidized bed, $9.51 \mathrm{~kg}$ particles were piled up in the bottom of bed to a height of $0.8 \mathrm{~m}$ at the beginning of simulation, and for the other two turbulent fluidized beds, $0.384 \mathrm{~kg}$ and $2.15 \mathrm{~kg}$ particles were piled up to the heights of $0.75 \mathrm{~m}$ and $0.204 \mathrm{~m}$, respectively. The gas enters the bed from the bottom inlet with uniform velocity and exits from the top outlets, where atmospheric pressure was prescribed. The no-slip and the partial-slip boundary condition were prescribed for the gas phase and solid phase, respectively. The algebraic form of the granular temperature model is chosen in our simulations, since it can save computational time and has better numerical convergence. In addition, this option allows similar prediction as using the full granular energy balance model [9, 37-39]. The solids leaving the outlets were recirculated to the bottom through using user defined functions (UDF) to avoid serious solid entrainment. The averaged solid concentration in the dense bottom and solid flux at different heights were monitored to determine when the simulation reached quasi-steady state. We found those parameters converged to certain quasi-steady value after 20 seconds. Therefore, all simulations of reactors ran for $30 \mathrm{~s}$ and the data of the last $10 \mathrm{~s}$ were collected for averaging. More simulation settings are summarized in Table 4 and the drag formulations are provided in Supplementary material. 
1 Table 4 Simulation settings of three fluidized beds

\begin{tabular}{|c|c|c|c|}
\hline & Dubrawski et al. [33] & Venderbosch [6] & Gao et al. [36] \\
\hline Mean grid size, $\Delta$ & $198 d_{\mathrm{p}}, 162 d_{\mathrm{p}}, 112 d_{\mathrm{p}}$ & $67 d_{\mathrm{p}}, 45 d_{\mathrm{p}}$ & $62 d_{\mathrm{p}}, 51 d_{\mathrm{p}}, 41 d_{\mathrm{p}}$ \\
\hline Solid inventory, $\mathrm{kg}$ & 9.51 & 0.384 & 2.15 \\
\hline Initial bed height, $H_{0}, \mathrm{~m}$ & 0.8 & 0.75 & 0.204 \\
\hline Maximum solids fraction & 0.55 & 0.63 & 0.63 \\
\hline Unsteady formulation & \multicolumn{3}{|c|}{ Unsteady, 2nd-order Implicit } \\
\hline Pressure-velocity coupling & \multicolumn{3}{|c|}{ Phase coupled SIMPLE } \\
\hline Granular viscosity & \multicolumn{3}{|c|}{ Gidaspow } \\
\hline Granular bulk viscosity & \multicolumn{3}{|c|}{ Lun et al. } \\
\hline Frictional viscosity & \multicolumn{3}{|c|}{ Schaeffer } \\
\hline Granular temperature & \multicolumn{3}{|c|}{ Algebraic } \\
\hline Frictional pressure & \multicolumn{3}{|c|}{ Based KTGF } \\
\hline Solid pressure & \multicolumn{3}{|c|}{ Lun et al. } \\
\hline Radial distribution & \multicolumn{3}{|c|}{ Lun et al. } \\
\hline Angle of internal friction & \multicolumn{3}{|c|}{30} \\
\hline Drag model & \multicolumn{3}{|c|}{ Hong et al. [5]/This work } \\
\hline Time step & \multicolumn{3}{|c|}{$0.0005 \mathrm{~s}$} \\
\hline
\end{tabular}

2

$3 \quad 4.2$ Results and discussions

$4 \quad$ 4.2.1 Bubbling fluidized bed

$5 \quad$ Fig. 4 shows the effect of grid size when using both drag models for the bubbling fluidized 
1 bed by the axial profiles of solids volume fraction. Both drag models show good prediction and

2 weak dependence on the grid size. Fig. 5 shows the instantaneous and time-averaged distribution of

3 solid concentration under different resolutions when using both drag models. It is clear that

4 meso-scale structures in forms of bubbles or voids can be captured. The predicted expansion heights,

5 as summarized in Table 5, are determined by following the approach of Cloete et al. [40] and they

6 are also weakly dependent on the grid size.
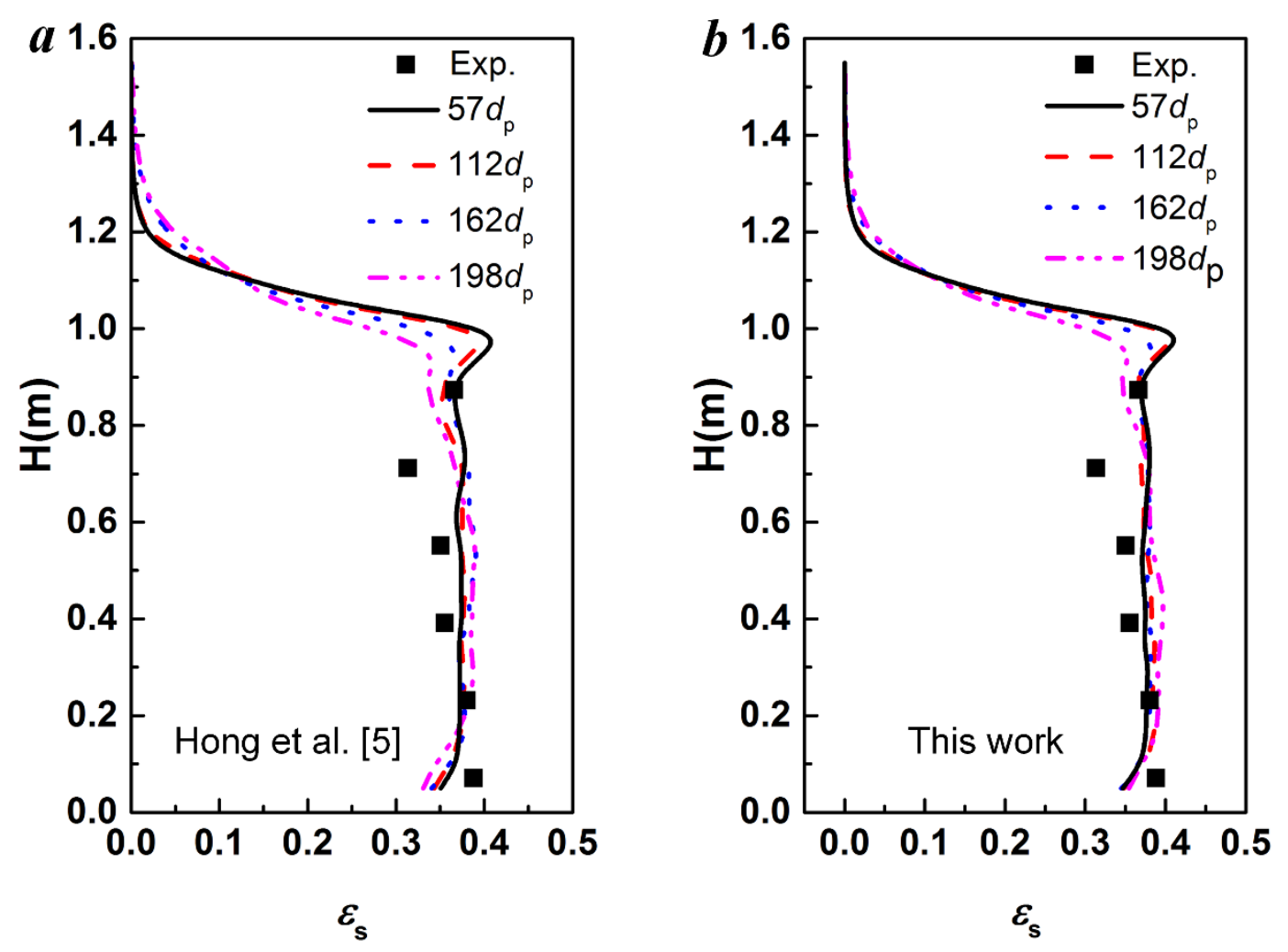

8 Fig. 4 Axial profiles of time-averaged solid concentration for bubbling fluidized bed of Dubrawski

9 et al. [33] under different grid resolutions by using drag models of (a) Hong et al. [5] and (b) this

10 work.

As shown in Fig. 5, both large and small bubbles are captured when using the finest grid resolution in the simulation. For the case of coarsest grid resolution, only large bubbles are captured. 
1 than the grid size can be captured in CFD simulation. Although different bubble behaviors are

2 captured by using different grid resolutions, such difference does not result in much different

3 time-averaged distribution of solid concentration, bed expansion and axial profiles of solid

4 concentration, suggesting that both structure-dependent drag models allow quantitative prediction

5 under coarse grid resolution though flow details are filtered. 

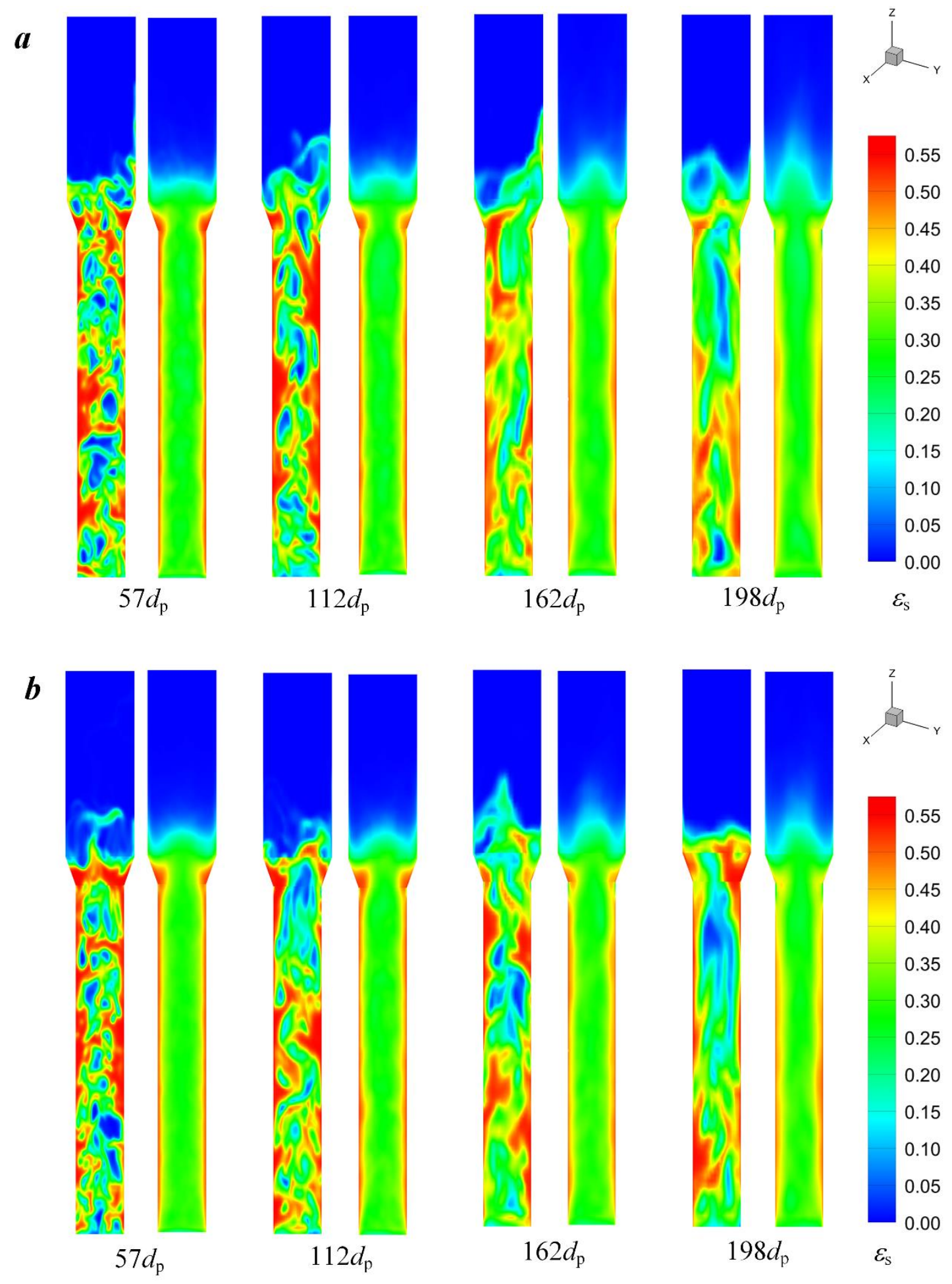

2 Fig. 5 Instantaneous and time-averaged distribution of solid concentration of the bubbling

3 fluidized bed of Dubrawski et al. [33] by using drag models of (a) Hong et al. [5] and (b) this

4 work. 
2 Table 5 Expansion heights predicted for the bubbling fluidized bed under different grid sizes

\begin{tabular}{cccc}
\hline & \multicolumn{3}{c}{ Expansion height (m) } \\
\cline { 2 - 4 } Grid size & Hong et al. [5] & This work & Exp. [41] \\
\cline { 2 - 4 } $57 d_{\mathrm{p}}$ & 1.155 & 1.152 & \\
$112 d_{\mathrm{p}}$ & 1.162 & 1.155 & 1.1 \\
$162 d_{\mathrm{p}}$ & 1.185 & 1.168 & \\
$198 d_{\mathrm{p}}$ & 1.203 & & \\
\hline
\end{tabular}

3

Fig.6 compares the radial profiles of solid concentration when using both drag models under

5 the coarsest resolution $\left(\Delta=198 d_{\mathrm{p}}\right)$. It is clear that both models capture the so-called core-annulus

6 flow structure. Quantitative comparison to experimental data shows that both drag models allow

7 reasonable prediction and their difference is small. This finding is consistent with the report of

8 Ghadirian et al. [42], as the bubbling fluidized bed is operated with low gas velocity and a narrow

9 distribution of slip velocity. Therefore, it is not surprising that the slip factor is not so significant

10 here. 

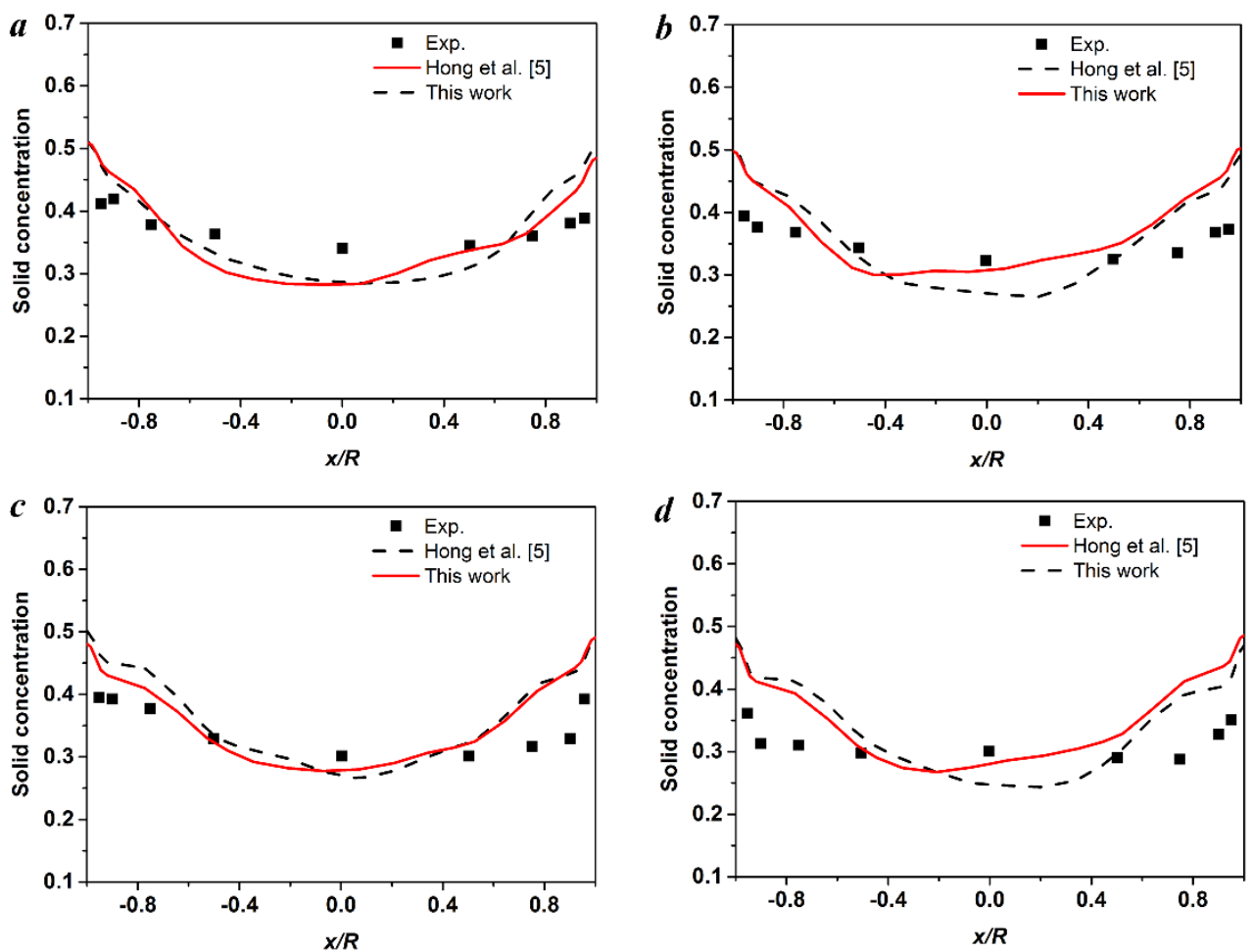

2 Fig. 6 Comparison of time-averaged radial profiles of solid concentration at the height of $(a) H=0.24$

$\mathrm{m},(b) H=0.4 \mathrm{~m},(c) H=0.56 \mathrm{~m}$ and $(d) H=0.72 \mathrm{~m}$.

\subsubsection{Turbulent fluidized bed}

In the following, we present results of two turbulent fluidized beds to further investigate the

effect of newly introduced slip factor on the grid dependence. Fig.7 shows time-averaged axial profiles of solid concentration and several slices of distribution of solids. Two drag models are

9 employed under two resolutions. When the EMMS/bubbling drag of Hong et al. [5] is employed, refining grid size from $67 d_{\mathrm{p}}$ to $45 d_{\mathrm{p}}$ obviously improves the prediction, especially in the dense bottom. Whereas for the new drag model, the prediction is less sensitive to the change of grid size and the axial profiles under both grid resolutions agree well with the experiment. 

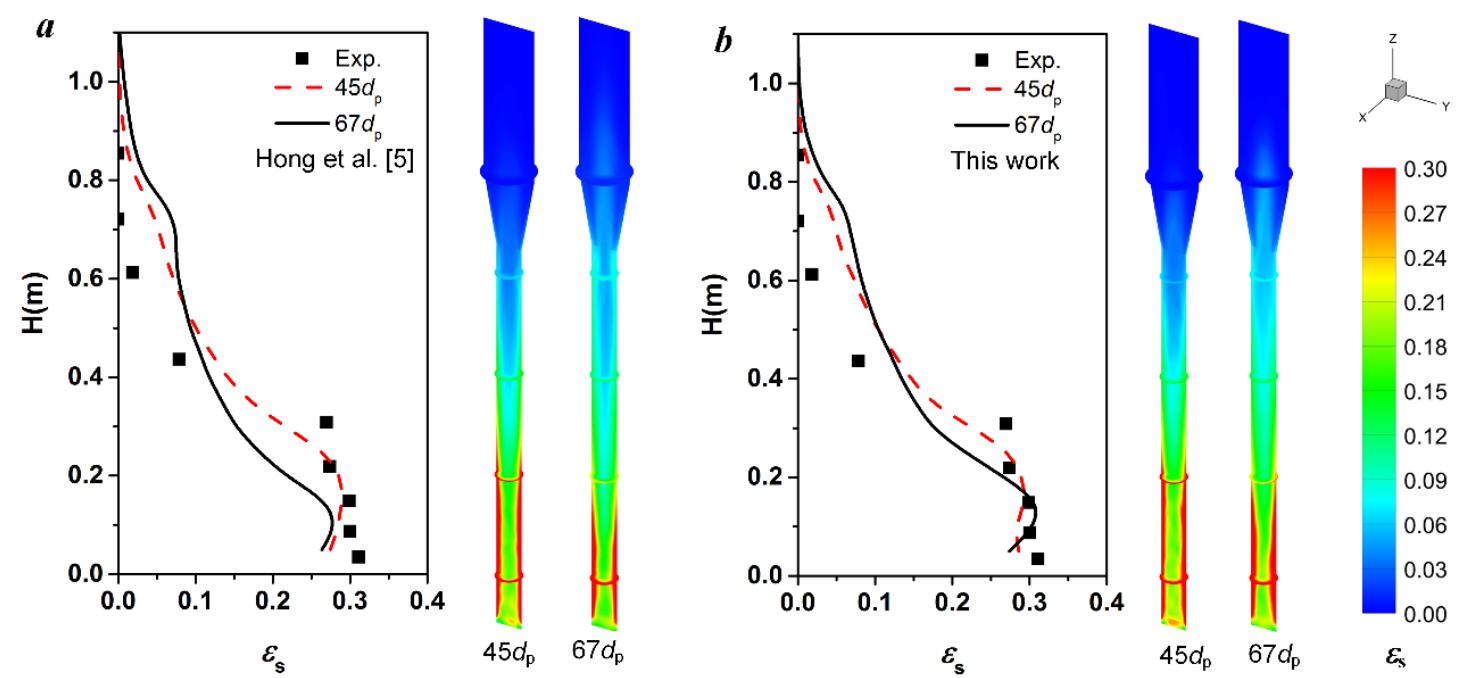

Fig. 7 Time-averaged axial profiles of solid concentration and distribution of solid concentration

3 over the whole turbulent fluidized bed of Venderbosch [6] when using (a) the drag of Hong et al. [5]

4 and (b) this work.

Compared to the case of Venderbosch, the fluidized bed of Gao et al. [36] is operated with higher gas velocity. The simulated axial profiles of time-averaged solid concentration by using both drag models are shown in Fig.8. Three grid resolutions were employed. For the EMMS/bubbling model of Hong et al. [5], the prediction improves with grid refinement. However, the case with finest resolution $\left(\Delta=41 d_{\mathrm{p}}\right)$ still underestimates the solid concentration in the bottom region and overestimates the solid concentration in the top of bed. When the new drag model is applied, the grid size has little effect on the predicted curves and at the same time the simulation results are much closer to the experiment, reflecting the contribution of the slip velocity. 

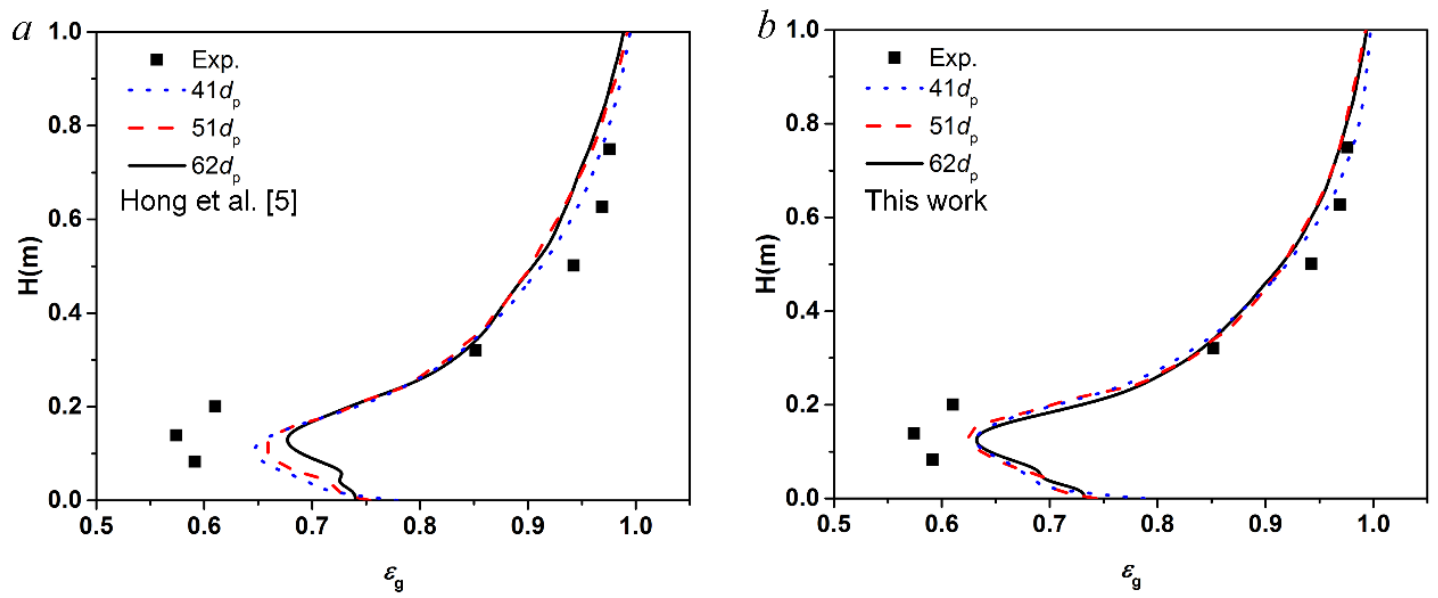

2 Fig. 8 Time-averaged axial profiles of solid concentration for turbulent fluidized bed of Gao et

3 al.[36] under different grid sizes by using the drag models of (a) Hong et al. [5] and (b) this work.

Fig. 9 shows the relative errors $\left(\mathrm{R}=\left|\varepsilon_{\mathrm{s}, \mathrm{c}}-\varepsilon_{\mathrm{s}, \mathrm{f}}\right| / \varepsilon_{\mathrm{s}, \mathrm{f}} \times 100 \%\right)$ of solid concentration. For the model

5 of Hong et al. [5], almost all the relative errors of solid concentration in the dense bottom exceed

$65 \%$ and some even larger than $10 \%$. By comparison, the relative errors of using the new drag model

7 are much smaller.

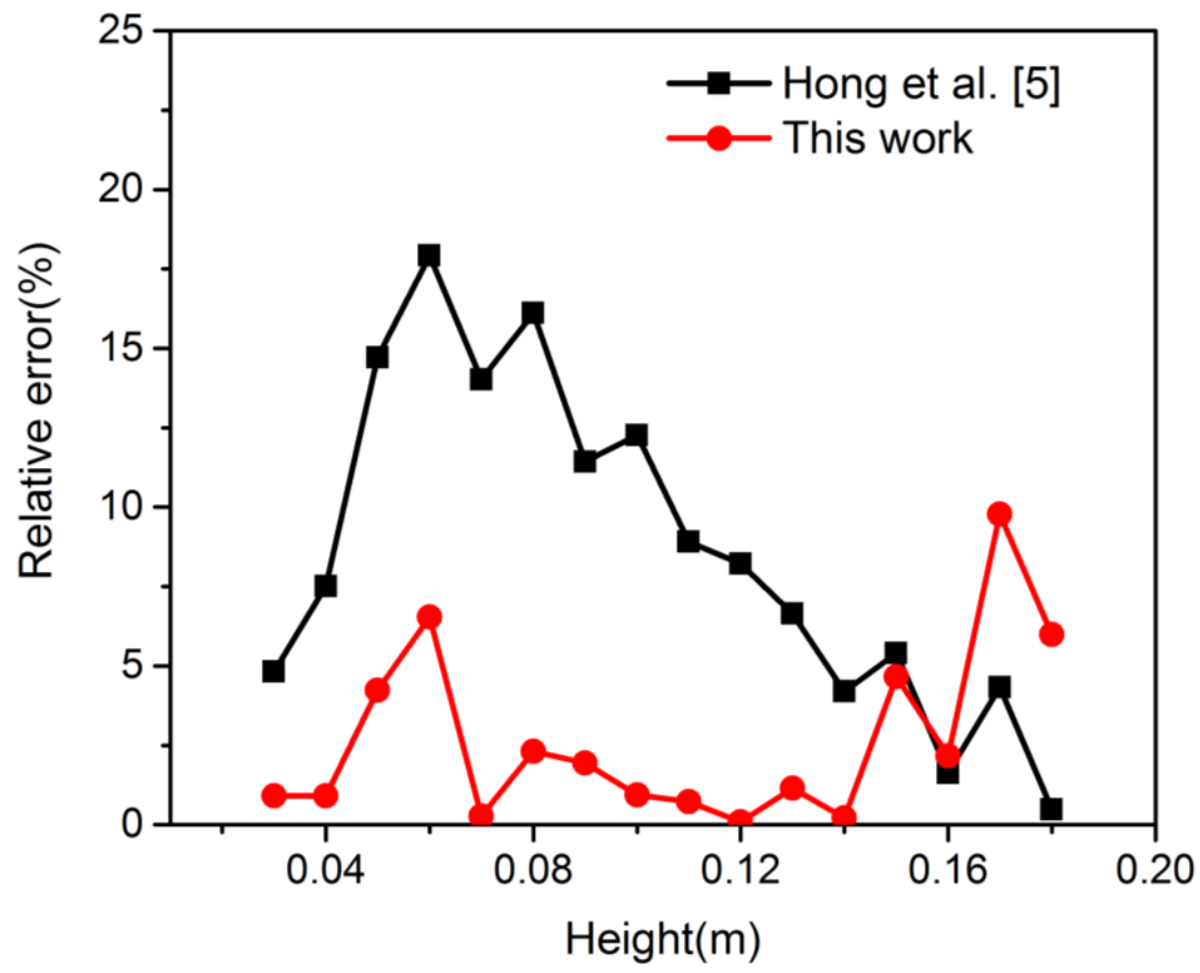

9 Fig. 9 The relative errors of solid concentration by using the model of Hong et al. [5] and new 
1 drag model (relative error $\mathrm{R}=\left|\varepsilon_{\mathrm{s}, \mathrm{c}}-\varepsilon_{\mathrm{s}, \mathrm{f}}\right| / \varepsilon_{\mathrm{s}, \mathrm{f}} \times 100 \%$, where $\varepsilon_{\mathrm{s}, \mathrm{c}}$ is solid concentration under the coarsest

2 grid resolution, and $\varepsilon_{\mathrm{s}, \mathrm{f}}$ under the finest grid resolution).

3 Fig.10 shows radial profiles of time-averaged solid concentration at different heights under

4 the coarsest grid resolution $\left(\Delta \approx 62 d_{\mathrm{p}}\right)$. At the lower positions of $H=0.078 \mathrm{~m}$ and $0.138 \mathrm{~m}$, the

5 prediction of the EMMS/bubbling model of Hong et al. [5] is generally lower than that of this

6 work in most regions, especially near the wall. At higher position of $0.338 \mathrm{~m}$, the results predicted

7 by using both drag models are close to each other. At even higher position of $H=0.478 \mathrm{~m}$, the new

8 drag model again shows better agreement with experimental data.
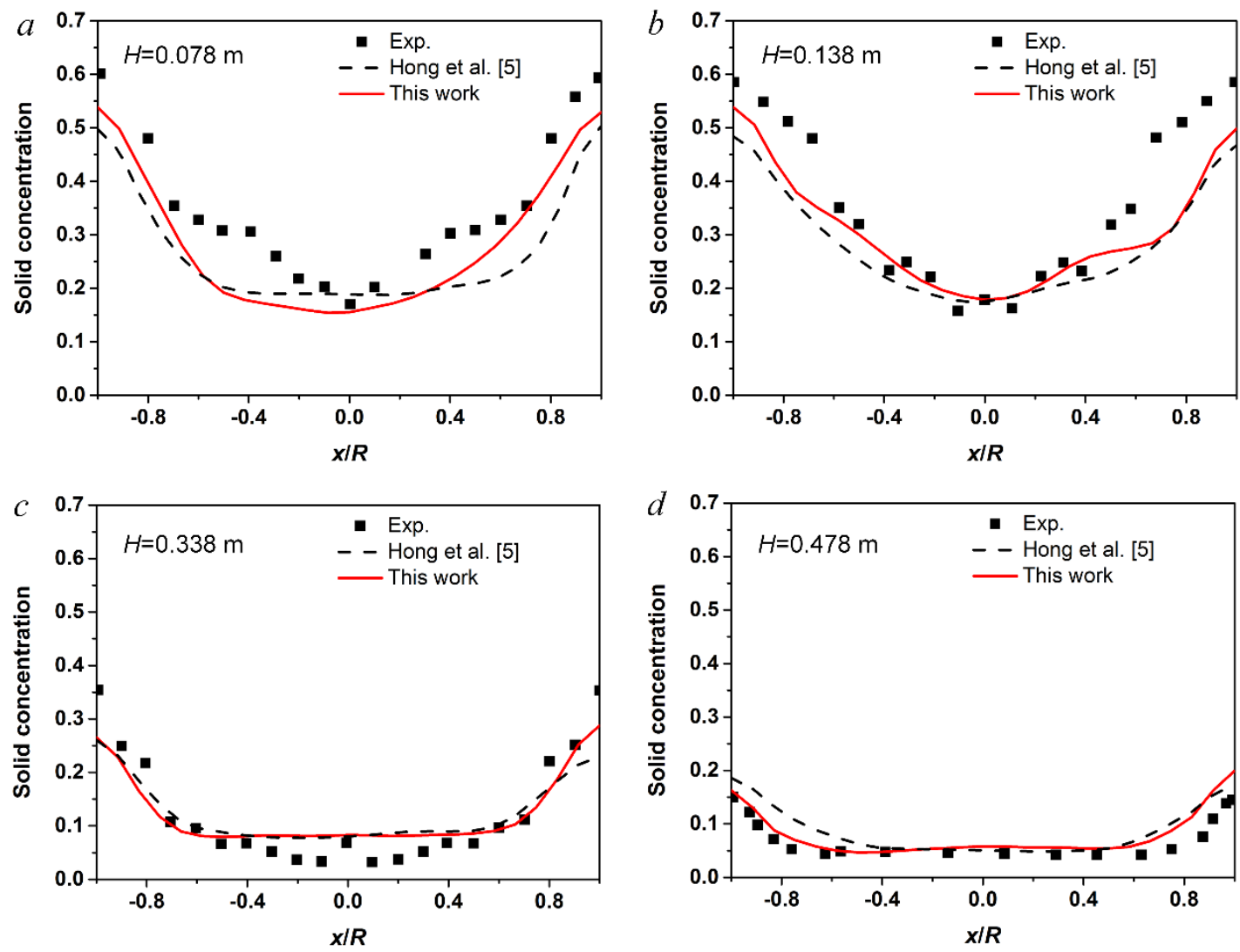

11 Fig. 10 The radial profiles of time-averaged solid concentration for turbulent fluidized bed of Gao et al. [36] at different heights: (a) $H=0.078 \mathrm{~m},(b) H=0.138 \mathrm{~m},(c) H=0.338 \mathrm{~m}$ and $(d) H=0.478 \mathrm{~m}$. 
The EMMS/bubbling drag model is extended to the sub-grid level by following the two-step

3 scheme of EMMS/matrix model. The heterogeneity index is therefore correlated as a function of

4 both local voidage and slip velocity. Simulations over a periodic domain show that the new drag

5 model is less sensitive to grid size because of the additional dependence on local slip velocity.

6 When applying the new drag model to simulations of realistic fluidized beds, we find that such

7 additional dependence on slip velocity enables better grid-independent results for high-velocity

8 turbulent fluidized beds. Compared to our previous EMMS/bubbling model, the new drag model

9 shows better qualitative agreement with experimental data.

\section{Nomenclature}

$\begin{array}{lll}a & \text { acceleration } & \mathrm{m} / \mathrm{s}^{2} \\ C_{\mathrm{d} 0} & \text { standard drag coefficient for a particle } & \\ C_{\mathrm{db}} & \text { standard drag coefficient for a bubble } & \\ C_{\mathrm{dc}} & \text { effective drag coefficient for a particle in dense phase } & \\ C_{\mathrm{dc} 0} & \text { standard drag coefficient for a particle in dense phase } & \\ C_{\mathrm{df}} & \text { effective drag coefficient for a particle in dilute phase } & \\ C_{\mathrm{df0}} & \text { standard drag coefficient for a particle in dilute phase } & \mathrm{m} \\ C_{\mathrm{db} 0} & \text { effective drag coefficient for a bubble } & \mathrm{m} \\ d_{\mathrm{b}} & \text { bubble diameter } & \mathrm{m} \\ d_{\mathrm{bm}} & \text { maximum bubble diameter } & \\ d_{\mathrm{p}} & \text { particle diameter } & \\ D_{\mathrm{t}} & \text { column diameter } & \mathrm{m} \\ & & \\ & & \end{array}$




\begin{tabular}{|c|c|c|}
\hline$F$ & drag force & $\mathrm{N}$ \\
\hline$f$ & volume fraction of dense phase & \\
\hline$g$ & gravity acceleration & $\mathrm{m} / \mathrm{s}^{2}$ \\
\hline$g_{0}$ & radial distribution function & \\
\hline$H$ & fluidized bed height & $\mathrm{m}$ \\
\hline$H_{\mathrm{D}}$ & heterogeneity index & \\
\hline$N_{\text {st }}$ & mass-specific energy consumption for suspending and & $\mathrm{W} / \mathrm{kg}$ \\
\hline & transporting particles & \\
\hline$N_{\mathrm{T}}$ & total mass-specific energy, & $\mathrm{W} / \mathrm{kg}$ \\
\hline$p$ & pressure & $\mathrm{Pa}$ \\
\hline $\operatorname{Re}$ & Reynolds number $\left(\operatorname{Re}=U_{\mathrm{r}} d_{\mathrm{p}} \rho_{\mathrm{g}} / \mu_{\mathrm{g}}\right)$ & \\
\hline RR & relative error & $\%$ \\
\hline$u$ & velocity & $\mathrm{m} / \mathrm{s}$ \\
\hline$u_{\mathrm{t}}$ & terminal velocity of a single particle & $\mathrm{m} / \mathrm{s}$ \\
\hline$U_{\mathrm{g}}$ & superficial gas velocity & $\mathrm{m} / \mathrm{s}$ \\
\hline$U_{\mathrm{s}}$ & superficial solid velocity & $\mathrm{m} / \mathrm{s}$ \\
\hline$U_{\mathrm{r}}$ & slip velocity & $\mathrm{m} / \mathrm{s}$ \\
\hline$U_{\mathrm{rc}}$ & slip velocity in dense phase & $\mathrm{m} / \mathrm{s}$ \\
\hline$U_{\mathrm{rf}}$ & slip velocity in dilute phase & $\mathrm{m} / \mathrm{s}$ \\
\hline$U_{\mathrm{ri}}$ & slip velocity in inter phase & $\mathrm{m} / \mathrm{s}$ \\
\hline
\end{tabular}




$\begin{array}{lll}\beta & \text { effective drag coefficient } & \mathrm{kg} /\left(\mathrm{m}^{3} \mathrm{~s}\right) \\ \beta_{0} & \text { Wen \& Yu drag coefficient } & \mathrm{kg} /\left(\mathrm{m}^{3} \mathrm{~s}\right) \\ \varepsilon & \text { voidage } & \\ \varepsilon_{\mathrm{mf}} & \text { minimum fluidization voidage } & \\ \mu & \text { viscosity } & \mathrm{Pa} \cdot \mathrm{s} \\ \rho & \text { density } & \mathrm{kg} / \mathrm{m}^{3}\end{array}$

$\begin{array}{ll}\text { b } & \text { bubble phase } \\ \text { f } & \text { dense phase } \\ \text { g } & \text { dilute phase } \\ \text { gc } & \text { dense-phase gas } \\ \text { gf } & \text { dilute-phase gas } \\ \text { s } & \text { solid phase } \\ \text { sc } & \text { dense-phase solid } \\ \text { sf } & \text { dilute-phase solid }\end{array}$

\section{Acknowledgments}

5 This work is financially supported by the National Natural Science Foundation of China

6 under Grant nos. 21576263, 21625605 and 91334204, and the "Strategic Priority Research

7 Program" of Chinese Academy of Sciences under no. XDA07080202, and the Youth Innovation 
1 Promotion Association CAS no.2015033. 
3 [1] W. Wang, J. Li, Simulation of gas-solid two-phase flow by a multi-scale CFD approach-of the

4 EMMS model to the sub-grid level, Chem. Eng. Sci. 62 (2007) 208-231.

5 [2] J.R. Grace, Contacting modes and behaviour classification of gas-solid and other two-phase suspensions, Can. J. Chem. Eng. 64 (1986) 353-363.

7 [3] D. Kunii, O. Levenspiel, Fluidization Engineering 2nd ed., Butterworth-Heinemann, Boston, 81991.

[4] Z. Shi, W. Wang, J. Li, A bubble-based EMMS model for gas-solid bubbling fluidization, Chem.

Eng. Sci. 66 (2011) 5541-5555.

[5] K. Hong, Z. Shi, W. Wang, J. Li, A structure-dependent multi-fluid model (SFM) for heterogeneous gas-solid flow, Chem. Eng. Sci. 99 (2013) 191-202.

[6] R.H. Venderbosch, The role of clusters in gas-solids reactors. An experimental study, Universiteit Twente, 1998.

[7] K. Agrawal, P.N. Loezos, M. Syamlal, S. Sundaresan, The role of meso-scale structures in rapid gas-solid flows, J. Fluid. Mech. 445 (2001) 151-185.

[8] W. Wang, Y. Chen, Mesoscale Modeling: Beyond Local Equilibrium Assumption for Multiphase Flow, in: B.M. Guy, L. Jinghai (Eds.) Advances in Chemical Engineering, Academic Press, Burlington, 2015, pp. 193-277.

[9] K. Hong, S. Chen, W. Wang, J. Li, Fine-grid two-fluid modeling of fluidization of Geldart A particles, Powder Technol. 296 (2016) 2-16.

[10] M. Syamlal, S. Pannala, Multiphase Continuum Formulation for Gas-Solids Reacting Flows, 

Systems:Theory, Methods and Practice, IGI Global, New York, 2011, pp. 1-65.

[11] B. Lu, N. Zhang, W. Wang, J. Li, J.H. Chiu, S.G. Kang, 3-D full-loop simulation of an industrial-scale circulating fluidized-bed boiler, AlChE J. 59 (2013) 1108-1117.

[12] S. Schneiderbauer, S. Puttinger, S. Pirker, P. Aguayo, V. Kanellopoulos, CFD modeling and simulation of industrial scale olefin polymerization fluidized bed reactors, Chem. Eng. J. 264 (2015) $99-112$.

[13] S. Shah, K. Myöhänen, S. Kallio, J. Ritvanen, T. Hyppänen, CFD modeling of gas-solids flow in a large scale circulating fluidized bed furnace, Powder Technol. 274 (2015) 239-249.

[14] V. Jiradilok, D. Gidaspow, S. Damronglerd, W.J. Koves, R. Mostofi, Kinetic theory based CFD simulation of turbulent fluidization of FCC particles in a riser, Chem. Eng. Sci. 61 (2006) 55445559.

[15] J. Li, M. Kwauk, Particle-fluid two-phase flow: the energy-minimization multi-scale method, Metallurgical Industry Press, Beijing, 1994.

[16] B. Lu, W. Wang, J. Li, Searching for a mesh-independent sub-grid model for CFD simulation of gas-solid riser flows, Chem. Eng. Sci. 64 (2009) 3437-3447.

[17] J. Gao, X. Lan, Y. Fan, J. Chang, G. Wang, C. Lu, C. Xu, CFD modeling and validation of the turbulent fluidized bed of FCC particles, AlChE J. 55 (2009) 1680-1694.

[18] Y. Igci, S. Sundaresan, Constitutive models for filtered two-fluid models of fluidized gasparticle flows, Ind. Eng. Chem. Res. 50 (2011) 13190-13201.

[19] C.C. Milioli, F.E. Milioli, W. Holloway, K. Agrawal, S. Sundaresan, Filtered two-fluid models 
1 [20] P. Li, X. Lan, C. Xu, G. Wang, C. Lu, J. Gao, Drag models for simulating gas-solid flow in the turbulent fluidization of FCC particles, Particuology 7 (2009) 269-277.

[21] N. Zhang, B. Lu, W. Wang, J. Li, Virtual experimentation through 3D full-loop simulation of a circulating fluidized bed, Particuology 6 (2008) 529-539.

[22] N. Zhang, B. Lu, W. Wang, J. Li, 3D CFD simulation of hydrodynamics of a 150MW e circulating fluidized bed boiler, Chem. Eng. J. 162 (2010) 821-828.

[23] B. Lu, C. Cheng, W. Lu, W. Wang, Y. Xu, Numerical simulation of reaction process in MIP riser based on multi-scale model, CIESC J. (in Chinese) 6 (2013) 014.

[24] N. Yang, W. Wang, W. Ge, J. Li, CFD simulation of concurrent-up gas-solid flow in circulating fluidized beds with structure-dependent drag coefficient, Chem. Eng. J. 96 (2003) 71-80.

[25] N. Yang, W. Wang, W. Ge, J. Li, Choosing structure-dependent drag coefficient in modeling gas-solid two-phase flow, China Particuology. 1 (2003) 38-41.

[26] W. Wang, B. Lu, N. Zhang, Z. Shi, J. Li, A review of multiscale CFD for gas-solid CFB modeling, Int. J. Multiphase Flow 36 (2010) 109-118.

[27] S.S. Ozarkar, X. Yan, S. Wang, C.C. Milioli, F.E. Milioli, S. Sundaresan, Validation of filtered two-fluid models for gas-particle flows against experimental data from bubbling fluidized bed, Powder Technol. 284 (2015) 159-169.

[28] Y. Zhao, H. Li, M. Ye, Z. Liu, 3D numerical simulation of a large scale MTO fluidized bed reactor, Ind. Eng. Chem. Res. 52 (2013) 11354-11364.

[29] M. Horio, A. Nonaka, A generalized bubble diameter correlation for gas-solid fluidized beds, AlChE J. 33 (1987) 1865-1872.

[30] J. Gascón, C. Téllez, J. Herguido, H.A. Jakobsen, M. Menéndez, Modeling of fluidized bed 
reactors with two reaction zones, AlChE J. 52 (2006) 3911-3923.

2 [31] K. Hong, Z. Shi, A. Ullah, W. Wang, Extending the bubble-based EMMS model to CFB riser

3 simulations, Powder Technol. 266 (2014) 424-432.

4 [32] D.G. Thomas, Transport characteristics of suspension: VIII. A note on the viscosity of

5 Newtonian suspensions of uniform spherical particles, J. Colloid. Sci. 20 (1965) 267-277.

6 [33] K. Dubrawski, S. Tebianian, H.T. Bi, J. Chaouki, N. Ellis, R. Gerspacher, R. Jafari, A. Kantzas,

7 C. Lim, G.S. Patience, T. Pugsley, M.Z. Qi, J.X. Zhu, J.R. Grace, Traveling column for comparison

8 of invasive and non-invasive fluidization voidage measurement techniques, Powder Technol. 235

9 (2013) 203-220.

[34] Y. Igci, A.T. Andrews, S. Sundaresan, S. Pannala, T.J. Obrien, Filtered two-fluid models for

11 fluidized gas-particle suspensions, AlChE J. 54 (2008) 1431-1448.

12

[35] C. Tagliaferri, L. Mazzei, P. Lettieri, A. Marzocchella, G. Olivieri, P. Salatino, CFD simulation of bubbling fluidized bidisperse mixtures: Effect of integration methods and restitution coefficient, Chem. Eng. Sci. 102 (2013) 324-334.

[36] X. Gao, C. Wu, Y. Cheng, L. Wang, X. Li, Experimental and numerical investigation of solid behavior in a gas-solid turbulent fluidized bed, Powder Technol. 228 (2012) 1-13.

[37] B. Van Wachem, J. Schouten, C. Van den Bleek, R. Krishna, J. Sinclair, Comparative analysis of CFD models of dense gas-solid systems, AlChE J. 47 (2001) 1035-1051.

[38] A. Bakshi, C. Altantzis, A.F. Ghoniem, Towards accurate three-dimensional simulation of dense multi-phase flows using cylindrical coordinates, Powder Technol. 264 (2014) 242-255.

[39] X.-Z. Chen, D.-P. Shi, X. Gao, Z.-H. Luo, A fundamental CFD study of the gas-solid flow field in fluidized bed polymerization reactors, Powder Technol. 205 (2011) 276-288. 
1 [40] S. Cloete, S.T. Johansen, S. Amini, Investigation into the effect of simulating a 3D cylindrical

2 fluidized bed reactor on a 2D plane, Powder Technol. 239 (2013) 21-35.

3 [41] S. Vashisth, A.H. Ahmadi Motlagh, S. Tebianian, M. Salcudean, J.R. Grace, Comparison of

4 numerical approaches to model FCC particles in gas-solid bubbling fluidized bed, Chem. Eng. Sci.

$5134(2015) 269-286$.

6 [42] E. Ghadirian, H. Arastoopour, CFD simulation of a fluidized bed using the EMMS approach

7 for the gas-solid drag force, Powder Technol. 288 (2016) 35-44.

8 